\title{
Impact of Job Insecurity, Role Perception and Self Efficacy on Bankers' Affective Wellbeing
}

\author{
Aramide, Olufemi Kunle ${ }^{1}$, Adebisi, Kolawole Shittu², \\ Aderibigbe, John Kolawole ${ }^{3}$ \\ I'Department of General Studies/The Polytechnic, Ibadan, Nigeria) \\ ${ }^{2}$ (Department of General Studies/The Polytechnic, Ibadan, Nigeria) \\ ${ }^{3}$ (Department of Learning and Development/Chartered Institute of Personnel Management, Nigeria)
}

\begin{abstract}
This study investigated the impact of job insecurity, role perception and self efficacy on banker's affective wellbeing. Survey research redesign and quota sampling technique were adopted in this study. 250 male and female bankers participated while data was collected from using a validated questionnaire form. Two hypotheses were tested and results showed that role perception, job insecurity and self efficacy jointly predicted affective wellbeing $(F(3,202)=16.08 ; P<.05)$; self efficacy is the most independent predictor of affective wellbeing $(\beta=.29 ; t=4.16 ; P<.05)$; role perception $(\beta=.22 ; t=3.41 ; P<.05)$ also predicted affective wellbeing while job insecurity $(\beta=.01 ; t=0.21 ; P>.05)$ did not. However, results indicated that age, gender, years of experience and organizational tenure did not either jointly or independently predict affective wellbeing. Hence, it was recommended that managers in the banking sector should pay adequate attention to the salient psychological factor of job insecurity, role perception and self-efficacy of employees and ensure that they are well trained and sensitized on the necessity of putting on a high level of confidence in handling work-life situations, ascertain permanent employment status and enhance the positive perception of bankers as this positively increases their well-being.
\end{abstract}

Keywords: Affective Wellbeing, Bankers, Job Insecurity, Role Perception, Self-Efficacy.

\subsection{Nature of the Problem}

\section{Introduction}

There is no doubt that the work environment has changed dramatically in the last three decades of the $20^{\text {th }}$ Century. Employees are expected to give more in terms of time, efforts, commitment and flexibility while they may receive less in terms of job security, affective wellbeing and leisure time. A gradual violation of the psychological contract between organizations and their employees in gradually being entrenched and this is likely to produce burnout, because it eroded the notion of reciprocity, which is crucial in maintaining well being. In the last few years, the nature of banking work has change dramatically in Nigeria. The late $80 \mathrm{~s}$ and 90s saw the gradual introduction of new technology, especially computers in the work place. Most work that were manually done become computerized. This was following in the late 90 s and early 2000 by the forces of globalization. Globalization heralded global banking with all the attendant challenges for a developing nation life Nigeria. Banks and their customers head to adjust to the changing faces of banking brought about by the demand of the globalization world. The last five years have also brought new challenges to the banking industry. The banking consolidation exercise of 2006 have completely changed the operational basis of banking industry in Nigeria from 89 independent organizations, Nigeria banks have been reduced to a mere 25 through reorganizations, mergers and acquisitions. In the process, an estimated 55,000 bankers have either been retired, retrenched or summarily dismissed from employment. Those still in service are daily threatened by their employers with possible sack, casualization or demotion. All these have altered the climate in which bankers perform their jobs.

Wellbeing, though heterogeneous in meaning generally describes the confidence, happiness, the physical well being and general outlook of an individual. The term "well being" is related to such concepts as happiness, health, welfare, comfort, security and safety. Janse, Krol, Groothoff and Post (2004) suggest that "well being" is synonymous with "the quality of life" an individual lives. The consolidation exercise as it affected banks and bank workers no doubt negatively affected the quality of lives of many bankers. The trauma of job insecurity, having to work long hours in order to satisfy the demands of customers and the desperation to mobilize deposits to meet the demands of Central Bank left a salutary effect on Nigerian bank workers. In view of the importance of wellbeing, this study investigated impact of job insecurity, role perception and self-efficacy on affective wellbeing of bankers. 
Job insecurity has been described as a subjective phenomenon, i.e. it is based on the individual's perceptions and interpretations of the immediate work environment (Hartley, Jacobson, Klandermans \& Vuuren, 1991). Job insecurity refers to the anticipation of this stressful event in such a way that the nature and continued existence of one's job are perceived to be at risk, thereby implying that the feeling of job insecurity only occurs in the case of involuntary job loss. The feeling of job insecurity has been largely enhanced among bank workers by its widespread adoption among various banks. There is hardly any bank among the surviving 25 institutions of the post consolidation era that has not laid off a sizeable proportion of its staff. And when this happens, it creates fear and uncertainty among those still employed. In a nation where the unemployment rate is as high as $25 \%$, job loss is a serious cause for psychological trauma among Nigerians. Hartley, Jacobson, Klandermans and Vuuren, (1991) state that job insecurity reflects a fundamental and involuntary change concerning the continuity and security within the employing organization.

Ilgens and Hollenbeck (1991) define role as an expected pattern or set of behavior that exist in the minds of people. Organizations exist and function effectively because there is the definition of roles among the different members of the organization. Rogers and Rogers (1976) defined an organization as a stable system of individuals working together through a hierarchy of ranks and division of labour to achieve some common goals. It is the division of labour among members of the organization that creates specialization and role expectations. Workers are recruited into organizations based on their perceived competence in particular fields and their abilities to contribute to the success of organizational goals. Thus we have varied professionals like marketers, lawyers, banking operations professionals, accountants, engineers etc. within the banking industry. These various professionals are assigned to operate in different sections of the industry like marketing, product development, baking operations, loan recovery, internal control, human resource management etc. Formal organizational structure determines the role assigned to individuals within the organization and is thus the source of role expectation among workers.

Self efficacy on the other hand has been defined as "a personal judgement of how well one can execute courses of action required to deal with prospective situations' (Bandura 1982). It deals with the perceived capacity of an individual to effectively handle a prospective problematic situation or effectively perform well in an assigned role. According to Bandura $(1977,1986)$ expectations of personal efficacy determines whether an individual's copying behaviour will be initiated, how much task-related effort will be expended and how long that effort will be sustained despite disconfirming evidence. In other words, self efficacy determines how well an employee will perform in a given role and how much of his personal knowledge and experience will be brought to bear in handling diverse situations. An employee who believes himself to be highly efficacious in particular roles or fields will likely succeed in achieving set goals or targets more than others who lack this all important sense of efficacy.

\subsection{Previous Work}

Ryff (1995) provides a multi-dimensional model of well being which included six distinct components. The components are: Self Acceptance; Positive attitude towards the self acknowledges and accepts multiple aspects of self, including good and bad qualities; feels positive about past life. These attempts at defining well being were criticized for their lack of credible assessment procedures. They equally made diverse and extensive criteria for the establishment of well being which made it difficult to determine the essential features that will mark psychological well being. They were also considered to be too value laden in prescribing how to achieve an optimal psychological functioning state.

Hamburger (2008) reports that the term "well being" has been used interchangeably with such concepts as happiness, health, welfare, comfort, security and safety. Mohd (2011), using 310 academics from five big public universities in Malaysia, time 2 data were collected six month later from the consented respondent at Time 1 yield 194 academics. The study used hierarchical regression analyses to obtain the result. The study found that role overload and role ambiguity predicted strain over time but not role conflict. According to Posig and Kickul (2003), strain occurs mainly because of fatigue that results from pressure to comply with the set of demands. Significant research also consistently confirmed the relationship between role perceptions such as role ambiguity and conflict with stress, which is the opposite wellbeing (O’Driscoll \& Beehr, 1994), indicating that role ambiguity is an important antecedent factor for the development of burnout (Cordes \& Dougherty, 1993).

Hartley, Jacobson, Klandermans and Vuuren (1991) report that job insecurity has the potential of being more distressing to the individual than job loss while job loss is already known and the individual has to come to terms with the loss and copes with its outcomes. In the case of job insecurity, on the other hand, coping may be inhibited by the uncertainty of the event. The well being of an employee is also subject to his understanding and effectiveness in his role within his organization.

A long-term, ominous job insecurity is likely to have severe consequences for an employee's overall life situation in that economic and other highly valued aspects of life will be perceived as threatened (Hartley, Jacobson, Klandermans \& Vuuren 1991). It appears that job insecurity is associated with impaired well-being 
(Barling \& Kelloway, 1996; Hartley et al., 1991). Physical health complaints, mental distress, and work-toleisure carry-over increase proportionately with the level of job insecurity (Isaksson, Hellgren, \& Pettersson, 1998; Lim, 1996; Noer, 1993; Hartley et al., 1991). However, the relationships between job insecurity and employee reactions may not be as clear-cut as implied by this brief review. Hence, it may be that different aspects of job insecurity relate differently to these types of outcomes. Unfortunately, only a few studies report relationships of different job insecurity dimensions and outcomes.

Roskies and Louis-Guerin (1990) examined the relative importance of various aspects of job insecurity on mental health and found that danger about future working conditions was more strongly related to the outcomes than danger about demotion and termination. Hellgren, Sverke and Isaksson (1999) found that qualitative job danger was more strongly related to work attitudes while quantitative danger evidenced stronger relationships with different aspects of health complaints. Hartley et al. (1991) raised the important questions: "Does job insecurity cause lower job satisfaction and well-being? Or do employees with lower job satisfaction experience more job insecurity?".

In Sweden, Gerdtham and Johannesson (2001) found a direct positive association between education and the well-being; individuals with the highest educational qualifications were most likely to report the highest levels of well-being. In contrast, Caporale, Georgellis, Tsitsianis, and Yin. (2007) found a negative association between education and happiness using data from the European Social Survey. Compared with individuals without educational qualifications, higher levels of educational qualifications were associated with higher low level of well-being, controlling for socioeconomic and demographic factors including absolute income. However, when relative income was included in the analysis, the authors found contrasting results. This suggests that for individuals with more education, their level of well-being is particularly dependent on relative income. They differ from individuals with less education in that being relatively rich or poor makes more difference to their level of well-being. Perhaps this is because having high-level qualifications raises expectations about income, which are not always met.

Easterlin (2003) also found a positive association between education and well-being, but only at one point in time and not over the life course. His results showed that at any given age, individuals with higher levels of education are happier than those with lower levels of education. However, over the life course, there is no significant trend in happiness for those with higher levels of education or those with lower levels of education and there is no evidence to support a happiness differential by educational status. Although those fortunate enough to start out with higher income and education remain, on average, happier throughout the life cycle than those of lower socioeconomic status, there is no evidence for either group that happiness increases with income (although there is no empirical evidence linking happiness and enduring learning over the life course).

Hartog and Oosterbeek (1998) used data from a cohort of adults born in 1940 in Holland in the province of Noord-Brabant to investigate the relationship between education and happiness, controlling for wealth and health and early life circumstances. Their results indicated that the positive relationship between education and happiness reached a maximum for intermediate level of qualifications. The relationship between education and happiness was parabolic and it remained statistically significant only for intermediate qualifications and for a higher vocational qualification.

Some researchers purport that negative life events are more positively viewed with increasing age, supporting a linear relationship between age and psychological well-being (Ben-Zur, 2002; Hong \& Giannakopoulos, 1994), others maintain that unhappiness problems increase with age (Pillay \& Sargeant, 1999; Thomas \& Vindhya, 2000), while others advocate a curvilinear relationship (Warr, 1990).

Hong and Giannakopoulos (1994) found that, with independent analyses of their sample of 17 to 40year-old Australians residing in Sydney, age displayed a significant positive relationship with life satisfaction (the greatest predictors of life satisfaction were self-esteem and depression), indicating that older adults express higher life satisfaction than younger adults. Hong, Bianca, Bianca, and Bollington (1993) found in their three age groups (17-22, 23-29 and 30-40) that the older age groups had significantly higher levels of self-esteem than the younger group.

Hong and Giannakopoulos (1994) proposed that younger individuals were in the process of 'life formation' through asserting their independence, forming nuclear families and becoming their own person and developing a sense of self-worth, while older individuals were settled, mature and more tolerant of negative life events. Consequently, as individuals age, their tendency to view negative life events more positively increases.

Contrary to other findings with regard to gender, Lim, Teo, and Loo (2003) found women to experience higher levels of financial well-being than men. Research by Pinto, Mansfield, and Parente (2004) may support this, as their findings suggest that perceived financial well-being is related to a higher internal locus of control. Clark and Oswald (1994), Clark et al. (1996) have found that men are more likely than women to be observed at the higher end of the happiness index. However, Gerdtham and Johannesson (1997) found the opposite result using Swedish data. In contrast, Frey and Stutzer (2000) identified no gender difference using 
Swiss data. Similarly, whilst some studies have found that well-being is positively related to education (Clark et al., 2001; Frey and Stutzer, 2000; Gerdtham and Johannesson, 1997), other studies have found the converse (Clark and Oswald, 1994).

\subsection{Purpose of Study}

This study was concerned with investigating the impact of job insecurity, role perception and self efficacy to bankers' wellbeing. Specifically, the study examined:

- If there is a joint and independent prediction of bankers' affective wellbeing by self efficacy, role expectation and job insecurity.

- The joint and independent prediction of employee's age, sex, experience and job tenure will be investigated in this study.

\subsection{Contribution of the Study}

The importance of this study was viewed from its contribution to the organizational effectiveness of the banking industry through the drastic reduction of absenteeism, health cost that arises from employee poor wellbeing. Reducing organizational sources of stress naturally improves the morale, productivity, and, therefore, enhanced overall organizational efficiency. Recognizing the stress experience and expressing support for measures to reduce sources of stress demonstrates management concern about their employees' well-being.

This study is very important in that it contributes to existing literature on employees wellbeing. Thus this study hopes to provide empirical explanations for the organizational factors and employees contributions to their wellbeing. Also the issue of employees' poor wellbeing is critical as it may lead to the collapse of the banking industry if not checked, this study is important in providing experts, organizations and government with factors that could improve the performance of bank employees and organizational practices.

\subsection{Statement of Hypotheses}

1 Self efficacy, role perception and job insecurity will jointly and independently predict bankers' affective wellbeing.

2. Age, gender, years of experience and organizational tenure will jointly and independently predict bankers' affective wellbeing.

\subsection{Research Design}

\section{Research Methodology}

The research design for this study was survey design using the questionnaires in the process. This was employed to look at the phenomenon of wellbeing and its determinants only across the population of bankers. No independent variable was actively manipulated as the events have taken place and only the impact was measured. The independent variables are employee's perception of role, self efficacy and job insecurity while the dependent variable is employee's affective wellbeing. A self report questionnaire was used to gather the data as the researcher did not directly engage in active manipulation of the independent variables.

\subsection{Participants}

The population sample for the study was drawn from the total population of employees in the banking industry. The banking sector in Ibadan is divided into 4 business districts based on location of bank offices and these are Challenge-Ring Road, Dugbe, Bodija-UI and Iwo road. From the four business districts, 250 participants were sampled from 16 bank branches in Ibadan using the quota sampling technique. The bank branches from the Challenge- Ring Road district include Zenith, Access, Skye, GT Bank, and Ecobank. For Dugbe district, the branches of bank sampled were First Bank, Union Bank, UBA, FCMB and Keystone. For Bodija -UI district, the bank branches sampled were Afri Bank, Fin Bank and Enterprise Bank while Spring, Diamond Bank and Sterling Bank were sampled in Iwo road district. Fifteen questionnaires each were distributed in 14 branches of different banks and 20 in two branches. Among the 210 respondents, one hundred were male $(47.6 \%)$ and one hundred and ten were females $(52.4 \%)$. The ages ranged from 20 years to 51 years. The mean age is 32.45 years and the standard deviation is 6.435 . Average years spent in the organization is 5.52 years. The average year of experience is 6.93 years. Among the respondents, sixty four were single $(30.5 \%)$, one hundred and thirty seven were married $(65.2 \%)$, six were divorced $(2.9 \%)$ and three were widowed $(1.4 \%)$. Their educational qualification shows that one had SSCE certificate $(0.5 \%)$, twenty six had OND $(12.4 \%)$, one hundred and three had first degree (49.0\%) and eighty had post graduate degree (38.1\%).

\subsection{Instrumentation}

The study utilized only primary data. The primary data was gathered through the use of a self report questionnaire. The research instrument which is the questionnaire was divided into five sections. 
Section A: This section captures the demographic variables such as age, sex, marital status, years of experience and job tenure e.t.c.

Section B: This section measures job insecurity using the job insecurity questionnaire scale developed by Obeng and Ugboro (2002) which consist of 20 -items, using the Likert type scale of $1=$ strongly agree to $5=$ strongly disagree.

The scales have recorded 0.78 alpha in previous study (Obeng and Ugboro (2002).

Section C: This section measures role perception using a 12- scale developed by Rizzo, House, and Lirtzman (1970). Items were scored on a 5-point Likert- type scale ranging from "strongly agree" to "strongly disagree", and the average score across the six items is interpreted as directly proportional to the level of role conflict. A sample item is "At work, I know what exactly is expected of me." The reliability for this scale as measured by Cronbach's alpha was 0.937.

Section D: This section measures self efficacy using self-Efficacy scale (SES) developed by Sherer, Maddux, Mercandante, Prentice-Dunn, Jacobs and Rogers (1982), The questionnaire consisted of 12 items, with two subscales: general self- Efficacy and social self-efficacy. This measure was designed to assess general expectations of self-efficacy that are not tied to specific situations or behavior. Participants' read statements relating to their efficacious beliefs selected on scale of 1 to 5 if they disagreed or agreed with the statements. The items listed in the questionnaire centered on statements about a person's determination to persevere in the face of difficulty. The underlying assumptions of this scale are that personal expectation of mastering a task are crucial factors In behavioral change, in addition, they also asserted that differences in past experiences of success lead to various levels of self-efficacy expectations (Sherer et al., 1982). The reliability from study is 0.922 alpha.

Section E: This section measures employees affective well being using the job-related Affective well-being scale, JAWS by Van Katwyt, Fox, Spector, \& Kelloway, (2000). It is a 20-items (short version) scale designed to assess people's emotional reactions to their job. Each item is an emotion, and respondents are asked how often they have experienced each at work over the prior 30 days.

Responses are made with a five-point scale anchor 1- Never, 2- Rarely, 3 -Sometimes, 4 - Quite often, 5- Extremely often or always. The JAWS includes a wide variety of emotional experiences both negative and positive. The emotions can be placed into four categories (subscales) that fall along two dimensions: pleasurableness and arousal (intensity). Internal consistency reliability estimates (coefficient alpha) available from three studies are .92, .94 and 95 (Bruk-lee 7 Spector, in press; Spector, Fox Goh, \& Bruursema, 2003; Van Katwyk et al., 2000). For this study the scale reliability was 0.954 .

\subsection{Procedure}

The research started with relevant review of literatures. The researcher proceeded to the field where the study actually took place. The managers of the various branches of the banks were of great assistance as approval to distribute the questionnaire were sought from them after explaining the main aim of the research work to them. The questionnaires were distributed to the respondents who are staff of the various banks. The questionnaires were administered to the respondents at their various places of work and collected immediately except for some which the researcher had to go back for two to three weeks later. The process of distributing and retrieving the questionnaires lasted for three weeks. A total number of two hundred and fifty questionnaires were distributed and two hundred and ten were retrieved from the respondents which was $84 \%$ response rate. These questionnaires were submitted for statistical analysis and the outcome is presented in chapter four of the research work.

\subsection{Statistics Analysis}

Hypothesis one and two were analyzed using multiple regression analysis

\section{Figures And Tables}

Results of statistical analysis of data collected based on the stated hypotheses are presented below:

First hypothesis which stated that self efficacy, role perception and job insecurity would jointly and independently predict bankers' wellbeing was tested using multiple regression analysis. Results are presented in summary table below.

Table 3.1 Summary Of Multiple Regression Analysis Showing The Influence Of Role Perception, Self Efficacy And Perceived Job Insecurity On Affective Wellbeing

\begin{tabular}{|c|c|c|c|c|c|c|}
\hline PREDICTORS & $\mathbf{R}$ & $\mathbf{R}^{2}$ & B & $\mathbf{T}$ & $\mathbf{F}$ & $\mathbf{P}$ \\
\hline JOB INSECURITY & \multirow{3}{*}{.44} & \multirow{3}{*}{.19} & .014 & .214 & \multirow{3}{*}{16.084} & \multirow{3}{*}{$<0.05$} \\
\hline SELF EFFICACY & & & .294 & 4.162 & & \\
\hline ROLE PERCEPTION & & & .220 & 3.141 & & \\
\hline
\end{tabular}


The result in table 4.1, showed that role perception, job insecurity and self efficacy jointly predicted bankers' affective wellbeing. The three variables were collectively responsible for $19 \%$ change observed in bankers' affective wellbeing $(\mathrm{F}(3,202)=16.08 ; \mathrm{P}<.05)$. Also, the result showed that self efficacy is the most independent predictor of affective wellbeing $(\beta=.29 ; \mathrm{t}=4.16 ; \mathrm{P}<.05)$. Role conflict $(\beta=.22 ; \mathrm{t}=3.41 ; \mathrm{P}<.05)$ also independently predicts affective wellbeing. While job insecurity $(\beta=.01 ; \mathrm{t}=0.21 ; \mathrm{P}>.05)$ did not independently predict bankers' affective wellbeing, thus, the hypothesis is partially supported.

The second hypothesis which states that age, gender, years of experience and organizational tenure will jointly and independently predict bankers' affective wellbeing was also analyzed using multiple regression analysis. Result is presented in the summary table two below.

Table 3.2 Summary Of Multiple Regression Analysis Showing The Influence Of Age, Gender, Years Of Experience And Organizational Tenure On Bankers' Affective Well Being

\begin{tabular}{|c|c|c|c|c|c|c|}
\hline PREDICTORS & $\mathbf{R}$ & $\mathbf{R}^{2}$ & B & $\mathbf{T}$ & $\mathbf{F}$ & $\mathbf{P}$ \\
\hline AGE & \multirow{4}{*}{.13} & \multirow{4}{*}{.02} & -.031 & -.259 & \multirow{4}{*}{.879} & \multirow{4}{*}{$>0.05$} \\
\hline SEX & & & .113 & .598 & & \\
\hline YEARS SPENT & & & -.054 & -.353 & & \\
\hline YEARS OF EXPERIENCE & & & .031 & .174 & & \\
\hline
\end{tabular}

The result in table 4.2, found that there was no significant joint prediction of bankers' affective wellbeing by age, gender, years of experience and organizational tenure jointly predicted employees' affective wellbeing. The variables were collectively responsible for $2 \%$ of the change observed in the reported employees' affective wellbeing $(\mathrm{F}(4,203)=.879 ; \mathrm{P}>.05)$. The result also demonstrated that the independent influence of age, gender, years spent in organization and years of experience was found not statistically significant. Thus this hypothesis is not supported.

\section{CONCLUSION}

\subsection{Discussion}

The variables of job insecurity, role perception and self efficacy were collectively responsible for $19 \%$ change observed in reported employees' affective wellbeing. Suggesting that role perception, job insecurity and self efficacy significantly determine some level of affective wellbeing among employees sampled in this study. Also, the result shows that self efficacy is the most significant independent predictor of affective wellbeing among the three variables role perception, job insecurity and self efficacy. This implies that self efficacy is the most important influence on employees, and the effect of job insecurity and perceived role constraints have negligible effect on employees' affective wellbeing. Job insecurity and role perception effect were found not to be significant in determining the level of affective wellbeing.

This result confirmed that self efficacy plays significant mediating role in stressful events outcome (Jex \& Bliese 1999). These findings depict the Nigerians banking environment, which relies on people who are aggressively confident. This personally is what is believed to make people succeed in their everyday task as banking job is believed to be very challenging and tasking. Thus people who are unable to cope with the pressure often become disoriented when they face ambiguous situations and role conflicts. This findings is in line with findings of Warr's (1987) view that self-efficacy is able to influence affective reactions to tasks and motivation thus influencing affective wellbeing and job performance. Ryff (1995) provides a multi-dimensional model of well being which included six distinct components. The components are: Self Acceptance; Positive attitude towards the self acknowledges and accepts multiple aspects of self, including good and bad qualities; feels positive about past life. These attempts at defining well being were criticized for their lack of credible assessment procedures. They equally made diverse and extensive criteria for the establishment of well being which made it difficult to determine the essential features that will mark psychological well being. They were also considered to be too value laden in prescribing how to achieve an optimal psychological functioning state. Hamburger (2008) reports that the term "well being" has been used interchangeably with such concepts as happiness, health, welfare, comfort, security and safety. Mohd (2011), using 310 academics from five big public universities in Malaysia, time 2 data were collected six month later from the consented respondent at Time 1 yield 194 academics. The study used hierarchical regression analyses to obtain the result. The study found that role overload and role ambiguity predicted strain over time but not role conflict. According to Posig and Kickul (2003), strain occurs mainly because of fatigue that results from pressure to comply with the set of demands. Significant research also consistently confirmed the relationship between role perceptions such as role ambiguity and conflict with stress, which is the opposite wellbeing (O'Driscoll \& Beehr, 1994), indicating that role ambiguity is an important antecedent factor for the development of burnout (Cordes \& Dougherty, 1993). However, Hartley, Jacobson, Klandermans and Vuuren (1991) report that job insecurity has the potential of being more distressing to the individual than job loss while job loss is already known and the individual has to come to terms with the loss and copes with its outcomes. In the case of job insecurity, on the other hand, coping 
may be inhibited by the uncertainty of the event. The well being of an employee is also subject to his understanding and effectiveness in his role within his organization.

The second hypothesis which stated that the contributions of the demographic variables of ages, gender, years of experience and years spent in organization jointly and independently predict bankers' affective wellbeing was found not significant. The result shows that age, gender, years of experience and years spent in organization jointly does not predict employees' affective wellbeing. When combined, the variables were collectively responsible for $2 \%$ of the change observed in the reported employees' affective wellbeing. This shows that demographic factors do not significantly contribute to employees' wellbeing. These results are contrary to the findings of In Sweden, Gerdtham and Johannesson (2001) found a direct positive association between education and the well-being; individuals with the highest educational qualifications were most likely to report the highest levels of well-being. In contrast, Caporale, Georgellis, Tsitsianis, and Yin. (2007) found a negative association between education and happiness using data from the European Social Survey. Compared with individuals without educational qualifications, higher levels of educational qualifications were associated with higher low level of well-being, controlling for socioeconomic and demographic factors including absolute income. However, when relative income was included in the analysis, the authors found contrasting results. This suggests that for individuals with more education, their level of well-being is particularly dependent on relative income. They differ from individuals with less education in that being relatively rich or poor makes more difference to their level of well-being. Perhaps this is because having high-level qualifications raises expectations about income, which are not always met.

Easterlin (2003) also found a positive association between education and well-being, but only at one point in time and not over the life course. His results showed that at any given age, individuals with higher levels of education are happier than those with lower levels of education. However, over the life course, there is no significant trend in happiness for those with higher levels of education or those with lower levels of education and there is no evidence to support a happiness differential by educational status. Although those fortunate enough to start out with higher income and education remain, on average, happier throughout the life cycle than those of lower socioeconomic status, there is no evidence for either group that happiness increases with income (although there is no empirical evidence linking happiness and enduring learning over the life course). Hartog and Oosterbeek (1998) used data from a cohort of adults born in 1940 in Holland in the province of Noord-Brabant to investigate the relationship between education and happiness, controlling for wealth and health and early life circumstances. Their results indicated that the positive relationship between education and happiness reached a maximum for intermediate level of qualifications. The relationship between education and happiness was parabolic and it remained statistically significant only for intermediate qualifications and for a higher vocational qualification.

Some researchers purport that negative life events are more positively viewed with increasing age, supporting a linear relationship between age and psychological well-being (Ben-Zur, 2002; Hong \& Giannakopoulos, 1994), others maintain that unhappiness problems increase with age (Pillay \& Sargeant, 1999; Thomas \& Vindhya, 2000), while others advocate a curvilinear relationship (Warr, 1990). Hong and Giannakopoulos (1994) found that, with independent analyses of their sample of 17 to 40-year-old Australians residing in Sydney, age displayed a significant positive relationship with life satisfaction (the greatest predictors of life satisfaction were self-esteem and depression), indicating that older adults express higher life satisfaction than younger adults. Hong, Bianca, Bianca, and Bollington (1993) found in their three age groups (17-22, 23-29 and 30-40) that the older age groups had significantly higher levels of self-esteem than the younger group. Hong and Giannakopoulos (1994) proposed that younger individuals were in the process of 'life formation' through asserting their independence, forming nuclear families and becoming their own person and developing a sense of self-worth, while older individuals were settled, mature and more tolerant of negative life events. Consequently, as individuals age, their tendency to view negative life events more positively increases.

Contrary to other findings with regard to gender, Lim, Teo, and Loo (2003) found women to experience higher levels of financial well-being than men. Research by Pinto, Mansfield, and Parente (2004) may support this, as their findings suggest that perceived financial well-being is related to a higher internal locus of control. Clark and Oswald (1994), Clark et al. (1996) have found that men are more likely than women to be observed at the higher end of the happiness index. However, Gerdtham and Johannesson (1997) found the opposite result using Swedish data. In contrast, Frey and Stutzer (2000) identified no gender difference using Swiss data. Similarly, whilst some studies have found that well-being is positively related to education (Clark et al., 2001; Frey and Stutzer, 2000; Gerdtham and Johannesson, 1997), other studies have found the converse (Clark and Oswald, 1994).

\subsection{Conclusion}

It was therefore concluded in this study based on the findings above that:

1. Role perception, job insecurity and self efficacy jointly predicted bankers' affective wellbeing. 
2. Role perception and self efficacy independently predicted bankers' affective wellbeing.

3. Job insecurity did not predict bankers' affective wellbeing.

4. Age, gender, years of experience and organizational tenure did not predict bankers' affective wellbeing

\subsection{Recommendations}

In view of the above researchers therefore, suggested that managers in the banking sector should pay adequate attention to the salient psychological factor of self-efficacy of employees and ensure that they are well trained and sensitized on the necessity of putting on self confidence in handling work-life situations as this significantly affect their affective well-being. Doing this would enable the employees to be fully compose and comport themselves for their work duties and assignments.

\subsection{Limitation of the Study}

The following challenges were faced in this course of this study:

- Administration of questionnaire was limited to bankers.

- The time allotted to this study was short considering the nature of work of the participants and what the study was set out to achieve.

- Some participants did not fill or return the given questionnaire.

\subsection{Suggestions for Further Studies.}

Researchers also suggest that manager should design roles for employees to play at work such that would bring about clash of one job role with another. Thus, employees would vividly identify all work related roles in the job and know who and who perform each role at every point in time.

\section{REFERENCES}

[1] Bandura, A. (1982). Self- efficacy mechanism in human agency. American psychologist, 37, $122-147$.

[2] Bandura, A. (1986). Social foundations of thought and action. Engle-wood Cliffs, NJ: Prentice- Hall.

[3] Bandura, A.(1977). Self: Toward a unifying theory of behavioural change. Psychological Review, 84, 191-215.

[4] Barling, J., and Kelloway, K.E. (1996). Job insecurity and health: The moderating role of workplace control. Stress Medicine, 12, 253259.

[5] Ben-Zur, H. (2002). Coping, affect and aging: the roles of mastery and self-esteem. Personality and Individual Differences, 32, 357-372.

[6] Caporale, G.M., Georgellis, Y., Tsitsianis, N. and Yin, Y.P. (2007). Income and happiness across Europe: Do reference values matter? Brunel University, Mimeo.

[7] Clark, A. E. and Oswald, A. J. (1996). Satisfaction and comparison income. Journal of Public Economics, 61: 359-381.

[8] Clark, A., \& Oswald, A. (1994). Unhappiness and Unemployment. The Economic Journal, 104(424), 648-659.

[9] Cordes, C., \& Dougherty, T. W. 1993. A review and an integration of research on job burnout. Academy of Management Review ,18: 621-656.

[10] Easterlin, R. (2003). Explaining happiness. Special series of inaugural articles by members of the National Academy of Sciences. May 23, 2003.

[11] Frey, B. S., \& Stutzer, A. (2000). Happiness, economy and institutions. The Economic Journal, 110, 918-938.

[12] Gerdtham, U. G., and Johannesson, M. (2001). The relationship between happiness, health, and socio-economic factors: Results based on Swedish microdata. Journal of Socio-Economics, 30, 553-557.

[13] Hartley, J., Jacobson, D., Klandermans, P.G. and van Vuuren, C.V. (1991). Job insecurity: Coping with jobs at risk. London: Sage.

[14] Hartog, J. and Oosterbeek, H. (1998). Health, Wealth and Happiness: Why Pursue a Higher Education? Economics of Education Review, 17: 245-56.

[15] Hellgren, J., Sverke, M., and Isaksson, K. (1999). A two-dimensional approach to job insecurity: Consequences for employee attitudes and well-being. European Journal of Work and Organization Psychology, 8, 179-195.

[16] Hong, S. M., \& Giannakopoulos, E. (1994). The relationship of satisfaction with life to personality characteristics. The Journal of Psychology, 128, 547-558.

[17] Hong, S. M., Bianca, M. A., Bianca, M. R., \& Bollington, J. (1993). Self-esteem: The effects of life satisfaction, sex and age. Psychological Reports, 72, 95-101.

[18] Ilgen, D. R., and Hollenbeck, J. R. 1991. The structure of work: Job design and roles. In M. D. Dunnette, and L. M. Hough (Eds.), Handbook of Industrial and Organisational Psychology(2nd Edition), (pp. 165-207). California: Consulting Psychology Press.

[19] Isaksson, K., Hellgren, J., and Pettersson, P. (1998). Strukturomvandling inom svensk detaljhandel: Uppföljning av omorganization och personalminskning i KF/KDAB (Structural transformation in Swedish retail trade: Follow-up of a reorganization and layoff in KF/KDAB). Stockholm: Stockholm University (Reports from the Department of Psychology, No. 97/1998).

[20] Jansen D. E. M. C., Krol B., Groothoff J.W. \& Post D.(2004) People with an intellectual disability and their health problems: a review of comparative studies.Journal of Intellectual Disability Research 48, 93-102.

[21] Jex , S. M. \& Bliese, P.D. (1999). Efficacy beliefs as a moderator of the impact of work-related stressors: A multilevel study. Journal of Applied Psychology, 84, 349-361.

[22] Lim, V.K.G. (1996). Job insecurity and its outcomes: Moderating effects of workbased and nonwork-based social support. Human Relations, 2, 171-194.

[23] Lim, V.K.G., T.S.H. Teo and G. Loo, 2003. Sex,financial hardship and locus of control: an empirical study of attitudes towards money among Singaporean Chinese. Personality and Individual Differences, 34: 411-429.

[24] Mohd, K. I. (2011). Over Time Effects of Role Stress on Psychological Strain among Malaysian

[25] Noer, D. (1993). Healing the wounds: Overcoming the trauma of layoffs and revitalizingdownsized organizations. San Francisco: Jossey-Bass. Personality, 9, 185-211. 
[26] O'Driscoll, M. \& Beehr, T (1994). Supervisor behaviors, role stressors and uncertainty as predictors of personal outcomes for subordinates. Journal of Organizational Behaviour 15, 141-155.

[27] Pillay, A. L., \& Sargent, C. A. (1999). Relationship of age and education with anxiety, depression, and hopelessness in a South African community sample. Perceptual and Motor Skills, 89, 881-884.

[28] Pinto, M.B., D.H. Parente and P.M. Mansfield, 2005. Information learned from socialization agents: Its relationship to credit card use. Family and Consumer Science Research Journal, 33(4): 357-367.

[29] Posig, M., \& Kickul, J. (2003). Extending our understanding of burnout: test of an integrated model in nonservice occupations. Journal of Occupational Health Psychology.8(1), pp. 3-19.

[30] ublic University Academics: International Journal of Business and Social Science. Vol. 2, No.9. From www.ijbssnet.com.

[31] Rizzo, John R., Robert J., House, and Sidney I. Lirtzmanl (1970). "Role Conflict and Ambiguity in Complex Organizations". Administrative Science Quarterly 15 (March): 150-163.

[32] Rogers, E. M. \& Rogers, R. A. (1976). Communication in organizations. New York, NY: Free Press.

[33] Roskies, E., and Louis-Guerin, C. (1990). Job insecurity in managers: Antecedents and consequences. Journal of Organizational Behavior, 11,345-359.

[34] Ryff, C.D. (1995). Psychological well-being in adult life. Current Directions in Psychological Directions in Psychological Science, 4, 99-104.

[35] Sherer, M., Maddux, J.E., Mercadante, B., Prentice-Dunn, S., Jacobs, B., \& Rogers, R.W. (1982). The self Efficacy Scale: Construction and validation. Psychological Reports, 51, 663-671.

[36] Thomas, S., \& Vindhya, U. (2000). Women and stress: A study of stressful life events, depression and the moderating influence of self-esteem. Journal of Indian Psychology, 18, 38-51.

[37] Warr, P. B. (1990). The measurement of well-being and other aspects of mental health. Journal of Occupational Psychology, 57, 77-85.

[38] Warr, P. B. (2007). Work, happiness, and unhappiness. Mahwah, NJ: Erlbaum. 